\title{
Structural and morphological properties of metallic thin films grown by pulsed laser deposition for photocathode application
}

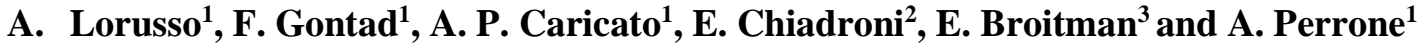 \\ ${ }^{1}$ Università del Salento, Dipartimento di Matematica e Fisica “E. De Giorgi” and Istituto Nazionale di Fisica \\ Nucleare, 73100 Lecce, Italy \\ ${ }^{2}$ Laboratori Nazionali di Frascati, Istituto Nazionale di Fisica Nucleare, 00044 Frascati, Italy \\ ${ }^{3}$ Department of Physics, Chemistry and Biology (IFM), Linköping University, SE-581 83 Linköping, Sweden \\ Corresponding author e-mail: francisco.gontad@le.infn.it
}

\begin{abstract}
In this work yttrium and lead thin films have been deposited by pulsed laser deposition technique and characterized by ex-situ different diagnostic methods. All the films were adherent to the substrates and revealed a polycrystalline structure. Y films were uniform with a very low roughness and droplet density while $\mathrm{Pb}$ thin films were characterized by a grain morphology with a relatively high roughness and droplet density. Such metallic materials are studied because they are proposed as a good alternative to copper and niobium photocathodes which are generally used in radiofrequency and superconducting radiofrequency guns, respectively. The photoemission performances of the photocathodes based on $\mathrm{Y}$ and $\mathrm{Pb}$ thin films have been also studied and discussed.
\end{abstract}

Key words: pulsed laser deposition; Y films; Pb films; metallic photocathodes. PACS: 52.38.Mf, 81.15.Fg

\section{INTRODUCTION}

R\&D of photocathodes is of great interest for the production of high brightness electron beam sources which are demanded, for example, for the new generation of X-ray free electron lasers and laser-plasma accelerators [1-3].

The radiofrequency (RF) and superconducting radiofrequency (SRF) cavities are usually made of copper $(\mathrm{Cu})$ and niobium $(\mathrm{Nb})$, respectively $[4,5]$. However, their relatively high work function and low quantum efficiency (QE) urge the search of alternative substances that may substitute them as the photoemitting material $[5,6]$. Among the alternative candidates, yttrium $(\mathrm{Y})$ and lead $(\mathrm{Pb})$ seem to be the more adequate choices due to their lower work functions and superior quantum efficiencies, with respect to $\mathrm{Cu}$ and $\mathrm{Nb}$, respectively [6]. 
The insertion of a small photo-emitting spot made of an alternative material with better photoemissive properties, such as $\mathrm{Y}$ or $\mathrm{Pb}$, seems to be a very noteworthy method to improve the photoemission performances of the cathode preserving the electrical properties of the cavity, i.e. its quality factor [7-13].

Pulsed laser deposition (PLD) technique got very interesting results for photocathode synthesis based on metallic thin films [14-17]. They are very adherent [18] to the substrates, even with depositions performed at room temperature, most likely due to high energy species of the plasma plume characterized by single and double charged states of ions [19, 20]. It is worth to say that the goal of obtaining good-quality thin films by this deposition technique, in terms of morphology and crystalline structure, is strongly related to the choice of experimental parameters, which have to be evaluated very carefully for each specific target material.

In this work $\mathrm{Y}$ and $\mathrm{Pb}$ thin films were grown by PLD on Si (100) for studying their morphology, roughness and thickness. $\mathrm{Y}$ and $\mathrm{Pb}$ thin films were also grown on polycrystalline $\mathrm{Cu}$ and $\mathrm{Nb}$ substrates, respectively, for QE testing.

\section{EXPERIMENTAL SET-UP}

The deposition of $\mathrm{Y}$ and $\mathrm{Pb}$ thin films was performed in a typical PLD high vacuum system described elsewhere [7]. Target and substrate were placed parallel inside the vacuum chamber, while the laser beam impinged at an angle of $45^{\circ}$ on the target surface, provoking the ablation of the target and, thus, the deposition of the ablated material on the substrate surface. The ablation of the targets was carried out with the third and fourth harmonics of a Q-switched Nd:YAG laser (Continuum Powerlite-8100), operating at a repetition rate of $10 \mathrm{~Hz}$. Due to the different chemical, physical and optical properties of the two targets ( $\mathrm{Y}$ and $\mathrm{Pb}$ ), the laser parameters for each deposition, chosen after detailed studies of the ablation and deposition processes, were slightly different as listed in Tables I and II.

Ablation of Y pure target (99.99\%) was achieved by using the third harmonic $(\lambda=355 \mathrm{~nm})$ of the Nd:YAG, with the deposition conditions listed in Table I.

In order to avoid deep crater formation and to keep the ablation rate as high as possible [21], the depositions were carried out with the cumulative effect of 40,000 laser pulses on two different concentric tracks, with 20,000 laser pulses per each track. A laser cleaning treatment of the target surface was applied, before the deposition, by 2,000 laser pulses for each track at the same energy density as used for the deposition of the $\mathrm{Y}$ thin film. During the target laser cleaning procedure, the substrate was shielded in order to avoid the transfer of the impurities. 
All $\mathrm{Pb}$ films were deposited by focusing the fourth harmonic $(\lambda=266 \mathrm{~nm})$ of the same laser on the target surface. The working laser fluence was chosen close to the laser ablation threshold of $\mathrm{Pb}, F_{\text {thr }}=0.52 \mathrm{~J} / \mathrm{cm}^{2}$ [18], in order to reduce the laser thermal effects on the target due to the relatively low melting point of such material $\left(327^{\circ} \mathrm{C}\right)$. The target-substrate distance was set at $4 \mathrm{~cm}$ in order to increase the deposition rate, as the low laser fluence constrained by the low melting point of $\mathrm{Pb}$ caused a low deposition rate with respect to $\mathrm{Y}$. The detailed experimental conditions are reported in Table II.

The adhesion of the films onto the substrates was evaluated by the tape test (known popularly as the "Scotch-tape method"), based on the standard ASTM D3359 [22], which consists in applying and removing an adhesive tape over a film. This empiric procedure classifies adhesion from $A$ to $C$, where $A$ is excellent and $C$ is poor.

A Scanning Electron Microscope (SEM, JEOL-JSM-6480LV) was used to observe the morphology of the films and to measure the thickness by cross sectional measurements. The reported root-mean-square (RMS) roughness values of the films were evaluated over an area of $5 \mu \mathrm{m} \times 5 \mu \mathrm{m}$ by AFM Park instrument (XE-70). Measurements were performed in non-contact mode using silicon rectangular probes with a tip radius $<10 \mathrm{~nm}$. The values have been calculated averaging over ten measurements.

The structure and crystal orientation of the films were studied by X-ray diffraction (XRD) measurements performed in the Bragg-Brentano geometry using a Rigaku D/MAX-Ultima diffractometer equipped with a MPA2000 thin film attachment stage and a $\mathrm{Cu}$ anode.

Finally, the QE was measured in a photodiode cell whose sketch is reported in Fig. 1. A detailed description of the apparatus is reported in Ref. [17]. The vacuum chamber, in which the photocathodes were inserted, was evacuated at a base pressure of about $2 \times 10^{-6} \mathrm{~Pa}$ by means of ionic and turbomolecular pumps. The photoemission was induced by UV radiation of $266 \mathrm{~nm}$ of wavelength. The energy density on the cathode was controlled by the adjustment of both the mask size and the telescopic focusing lens. The cathode was connected to the ground trough the resistance of $50 \Omega$ which was couplet to the oscilloscope for detecting the photoemission signals. The anode consisted of a copper ring of $25 \mathrm{~mm}$ in diameter separated from the photocathode at a distance of $3 \mathrm{~mm}$. The anode was biased at DC voltages up to $5 \mathrm{kV}$ thus allowing the generation inside the gap of a maximum electric field of about $1.7 \mathrm{MV} / \mathrm{m}$. 


\section{RESULTS AND DISCUSSION}

\subsection{Morphology and Structure}

Figure 2a) shows a SEM micrograph of a top view of the Y film characterized by a uniform and percolated morphology. It is worth to note that the droplets density on the film surface is very low. Figure 2b) reveals an interconnected and discontinue grain morphology of $\mathrm{Pb}$ thin film with the presence of several droplets on the film surface deriving directly from the melting material of the target.

Figure 3 displays the cross sectional images of the $\mathrm{Y}$ and $\mathrm{Pb}$ thin films from which it is possible to estimate the Y film thickness of about $1.2 \mu \mathrm{m}$ (Figure 3a) while the Pb thickness is about 300 nm (Figure 3b). Moreover, the images show that the Y film growth is characterized by a densely packed columnar structure with a very low RMS roughness value of about $2.0 \mathrm{~nm}$, while for $\mathrm{Pb}$ film the RMS roughness is evaluated of about $60 \mathrm{~nm}$. Photocathodes with a very low surface roughness are demanded for the production of high brightness electron beams.

Moreover, the adhesion of $\mathrm{Y}$ and $\mathrm{Pb}$ thin films on $\mathrm{Cu}$ and $\mathrm{Nb}$ substrates has been tested since a bad adhesion of the films means the uselessness of such devices as photocathodes. The deposited $\mathrm{Y}$ and $\mathrm{Pb}$ films were adherent to the respectively substrates. According to the tape test, the adhesion quality of both thin films was classified as $A$.

XRD patterns of Fig. 4 reveal a polycrystalline structure for both $\mathrm{Y}$ and $\mathrm{Pb}$ films. The XRD pattern of Fig. 4a) shows the polycrystallinity of the $\mathrm{Y}$ film which is typical of the hexagonal structure of Y as indicated by the clear presence of Y (100), Y (200) and Y (204) peaks [23]. The other peaks are attributed to the $\mathrm{Cu}$ substrate. Figure $4 \mathrm{~b}$ ) shows the XRD pattern of the $\mathrm{Pb}$ film deposited on Nb. In addition to the (110), (200) and (211) peaks of the Nb polycrystalline substrate, the figure shows a relatively intense peak at an angle of $31.30^{\circ}$, along with weaker peaks at $36.26^{\circ}, 52.24^{\circ}, 62.14^{\circ}, 65.24^{\circ}$ and $76.95^{\circ}$ ascribed to the $\mathrm{Pb}$ deposit in the cubic crystalline form. The peaks can be ascribed to the (111), (200), (220), (311), (222) and (400) planes of cubic $\mathrm{Pb}$ respectively [24].

\subsection{Quantum efficiency measurements}

Since $\mathrm{Y}$ and $\mathrm{Pb}$ are interesting for their photoemission performances, we studied $Q E$ of the photocathodes based on $\mathrm{Y}$ and $\mathrm{Pb}$ thin films. $Q E$ is defined as $Q E=N e / N p$, where $N e$ is the number of the photoemitted electrons and $N p$ is the number of the incident photons.

Figure 5 shows a linear relationship between the collected charge as a function of the laser energy for both photocathodes indicating that the photoelectron emission process occurs 
mainly via one-photon absorption mechanism, as predicted by the Fowler-DuBridge theory $[25,26]$. The continuous lines are the data fitting curve from which a $Q E$ of $3.3 \times 10^{-4}$ was estimated for Y photocathode (Fig. 5a) and a $Q E$ of $4 \times 10^{-5}$ for Pb photocathode (Fig. 5b). It is interesting to note in Fig. 5b) the data saturation, after about $250 \mathrm{pC}$ of collected charge, due to presence of space charge effects.

Table III summarizes the work function materials and $Q E$ of the photochatodes based on $Y$ and $\mathrm{Pb}$ thin films in comparison with those of $\mathrm{Cu}$ and $\mathrm{Nb}$ bulk. Here it must be stressed that the $\mathrm{QE}$ of a Y-based thin film photocathode is one-order of magnitude higher than using a Cu bulk substrate, while the $\mathrm{Pb}$-based thin film photocathode has a two-orders of magnitude higher $Q E$ than $\mathrm{Nb}$ bulk used as substrate. These interesting results confirm the idea to utilize $\mathrm{Y}$ and $\mathrm{Pb}$ thin films for the synthesis of cathodes with higher photoemission performances with respect to $\mathrm{Cu}$ and $\mathrm{Nb}$ materials conventionally used in RF and SRF guns.

\section{CONCLUSIONS}

$\mathrm{Y}$ and $\mathrm{Pb}$ thin films were grown by PLD technique on Si (100), Cu and Nb substrates for their potential photocathode application. The films were polycrystalline and very adherent to the substrates. Y thin films were uniform with a very low density of droplets and a RMS roughness of $2 \mathrm{~nm}$. On the contrary, $\mathrm{Pb}$ thin films were characterized by an interconnected and discontinue grain morphology, a relatively high RMS roughness and a high droplet density. Further studies will be necessary, in the future, to improve the quality of $\mathrm{Pb}$ thin films for their application as photocathodes. Photoemission measurements of $\mathrm{Y}$ and $\mathrm{Pb}$ thin films revealed QE values higher than the values of $\mathrm{Cu}$ and $\mathrm{Nb}$ bulks, respectively.

\section{ACKNOWLEDGMENTS}

This work was supported by the Italian National Institute of Nuclear Physics (INFN) and partially funded by the Italian Ministry of Research in the framework of FIRB 2012 - Fondo per gli Investimenti della Ricerca di Base, Project no. RBFR12NK5K. Esteban Broitman acknowledges the Swedish Government Strategic Research Area in Materials Science on Functional Materials at Linköping University (Faculty Grant SFO-Mat-LiU \# 2009-00971). The authors thank the technical support of Mr. D. Cannoletta for XRD measurements. 


\section{REFERENCES}

[1] C. P. Hauri, R. Ganter, F. Le Pimpec, A. Trisorio, C. Ruchert, H. H. Braun, Phys. Rev. Lett. 104, 234802 (2010).

[2] J. Smedley, T. Rao, J. Sekutowicz, Phys. Rev. ST Accel. Beams 11, 013502 (2008).

[3] K. Zhao, J. Hao, Y. Tang, K. Zhao, L. Wang, B. Zhang, J. Chen, Nucl. Instrum. Meth. A 445, 394 (2000).

[4] A. Cianchi et al., Phys. Rev. ST Accel. Beams 11, 032801 (2011).

[5] J. Smedley, T. Rao, Q. Zhao, J. Appl. Phys. 98, 043111 (2005).

[6] D. H. Dowell, I. Bazarov, B. Dunham, K. Harkay, C. Hernandez-Garcia, R. Legg. H. Padmore, T. Rao, J. Smedley, W. Wan, Nucl. Instrum. Meth. A 622, 685 (2010).

[7] A. Lorusso, F. Gontad, A. Perrone, N. Stankova, Phys. Rev. ST Accel. Beams 14, 090401 (2011).

[8] L. Cultrera, G. Gatti, P. Miglietta, F. Tazzioli, A. Perrone, J. T. Moody, P. Musumeci, Phys. Rev. ST Accel. Beams 12, 043502 (2009).

[9] J. P. Girardeau-Montaut, M. Afif, C. Tomas, A. F. Obaton, C. Girardeau-Montaut, K. Warda, Appl. Surf. Sci. 106, 451 (1996).

[10] H. J. Qian, J. B. Murphy, Y. Shen, C. X. Tang, X. J. Wang, Appl. Phys. Lett. 97, 253504 (2010).

[11] Q. Yuan, A. W. Baum, R. F. W. Pease, P. Pianetta, J. Vac. Sci. Technol. B 21, 2830 (2003).

[12] T. Nakajyo, J. Yang, F. Sakai, Y. Aoki, Jpn. J. of Appl. Phys. 42, 1470 (2003).

[13] X. J. Wang, T. Srinivasan-Rao, K. Batchelor, I. Ben-Zvi, J. Fischer, Nucl. Instrum. Meth. A 356, 159 (1995).

[14] L. Cultrera, C. Ristoscu, G. Gatti, P. Miglietta, F. Tazzioli, A. Perrone, J. Phys. D: Appl. Phys. 40, 5965 (2007).

[15] A. Lorusso, App. Phys. A 110, 869 (2013).

[16] F. Gontad, A Perrone, Nucl. Instrum. Meth. A 747, 1 (2014).

[17] A. Perrone, F. Gontad, A. Lorusso, M. Di Giulio, E. Broitman, M. Ferrario, Nucl. Instr. Meth. Phys. Res. A 729, 451 (2013).

[18] A. Lorusso, F. Gontad, E. Broitman, E. Chiadroni, A. Perrone, Thin Solid Films 579, 50 (2015).

[19] F. Gontad, A. Lorusso, A. Perrone, Thin Solid Films 520, 5211 (2012). 
[20] J. Krása, A. Lorusso, V. Nassisi, L. Velardi, A. Velyhan, Laser Part. Beams 29, 113 (2011).

[21] S. Di Mihai, A. Marcu, N. Puscas, Pulsed Laser Ablation of Solids: Basics, Theory and Applications (Springer-Heidelberg 2014, pag. 148).

[22] ASTM D3359-09e2, Standard Test Methods for Measuring Adhesion by Tape Test, ASTM International, West Conshohocken, PA, 2009, www.astm.org.

[23] PDF Card no. 65-1870, ICPDS-International Centre for Powder Diffraction Data, 2000.

[24] PDF Card no. 04-0686, ICPDS-International Centre for Powder Diffraction Data, 2000.

[25] R. H. Fowler, Phys. Rev. 38, 45 (1931).

[26] L. A. Dubridge, Phys. Rev. 43, 727 (1933). 


\section{FIGURE AND TABLE CAPTIONS}

TABLE I. Experimental conditions for deposition of Y thin films.

TABLE II. Experimental conditions for deposition of $\mathrm{Pb}$ thin films.

TABLE III. Work function of the materials and $Q E$ at photocathode drive laser of $266 \mathrm{~nm}$.

Figure 1. Photodiode apparatus for $Q E$ testing.

Figure 2. Plan-view SEM micrographs of (a) Y film and (b) Pb film on Si (100) substrates.

Figure 3. Cross sectional SEM images of (a) Y film and (b) Pb on Si (100) substrates. The Y and $\mathrm{Pb}$ thicknesses are about $1.2 \mu \mathrm{m}$ and $300 \mathrm{~nm}$, respectively.

Figure 4. $\theta-2 \theta$ XRD patterns of (a) $\mathrm{Y}$ film and (b) $\mathrm{Pb}$ film on $\mathrm{Cu}$ and $\mathrm{Nb}$ polycrystalline substrates, respectively.

Figure 5. Collected charge as a function of laser energy for (a) photocathode based on $\mathrm{Y}$ thin film and (b) photocathode based on $\mathrm{Pb}$ thin film. The continuous lines are the data fitting curves to estimate the $Q E$. 
TABLE I

\begin{tabular}{|c|c|c|}
\hline \multicolumn{2}{|l|}{ Target } & $\mathrm{Y}$ \\
\hline \multicolumn{2}{|c|}{ Substrate } & Si (100), Cu \\
\hline \multicolumn{2}{|c|}{ Substrate temperature } & $300 \mathrm{~K}$ \\
\hline \multicolumn{2}{|c|}{ Target-substrate distance } & $6 \mathrm{~cm}$ \\
\hline \multicolumn{2}{|c|}{ Laser spot size } & $2 \mathrm{~mm}$ \\
\hline \multicolumn{2}{|c|}{ Laser pulse duration } & $7 \mathrm{~ns}$ \\
\hline \multicolumn{2}{|c|}{ Laser fluence } & $3 \mathrm{~J} / \mathrm{cm}^{2}$ \\
\hline \multicolumn{2}{|c|}{ Laser wavelength } & Nd:YAG@355nm \\
\hline \multicolumn{2}{|c|}{ Repetition rate } & $10 \mathrm{~Hz}$ \\
\hline \multicolumn{2}{|c|}{ Background pressure } & $4.7 \times 10^{-6} \mathrm{~Pa}$ \\
\hline \multirow{2}{*}{$\begin{array}{l}\text { Laser } \\
\text { shots }\end{array}$} & Cleaning & $2 \times 2,000$ per track \\
\hline & Deposition & $2 \times 20,000$ per track \\
\hline
\end{tabular}

TABLE II

\begin{tabular}{|c|c|c|}
\hline \multicolumn{2}{|l|}{ Target } & $\mathrm{Pb}$ \\
\hline \multicolumn{2}{|c|}{ Substrate } & $\mathrm{Si}(100), \mathrm{Nb}$ \\
\hline \multicolumn{2}{|c|}{ Substrate temperature } & $300 \mathrm{~K}$ \\
\hline \multicolumn{2}{|c|}{ Target-substrate distance } & $4 \mathrm{~cm}$ \\
\hline \multicolumn{2}{|c|}{ Laser spot size } & $1.2 \mathrm{~mm}$ \\
\hline \multicolumn{2}{|c|}{ Laser pulse duration } & $7 \mathrm{~ns}$ \\
\hline \multicolumn{2}{|c|}{ Laser fluence } & $0.52 \mathrm{~J} / \mathrm{cm}^{2}$ \\
\hline \multicolumn{2}{|c|}{ Laser wavelength } & Nd:YAG@266 nm \\
\hline \multicolumn{2}{|c|}{ Repetition rate } & $10 \mathrm{~Hz}$ \\
\hline \multicolumn{2}{|c|}{ Background pressure } & $5.4 \times 10^{-6} \mathrm{~Pa}$ \\
\hline \multirow{2}{*}{$\begin{array}{l}\text { Laser } \\
\text { shots }\end{array}$} & Cleaning & 3,000 \\
\hline & Deposition & 15,000 \\
\hline
\end{tabular}




\section{Elements $\quad$ Work Function (eV) QE (@ 266 nm)}

\begin{tabular}{lll}
\hline $\mathrm{Cu}$ (bulk) & 4.6 & $1 \times 10^{-5}[6]$ \\
$\mathrm{Y}$ (film) & 3.0 & $3.3 \times 10^{-4}$ [this work] \\
$\mathrm{Nb}$ (bulk) & 4.4 & $7.4 \times 10^{-7}[5]$ \\
$\mathrm{Pb}($ film) & 4.0 & $4 \times 10^{-5}$ [this work $]$ \\
\hline
\end{tabular}

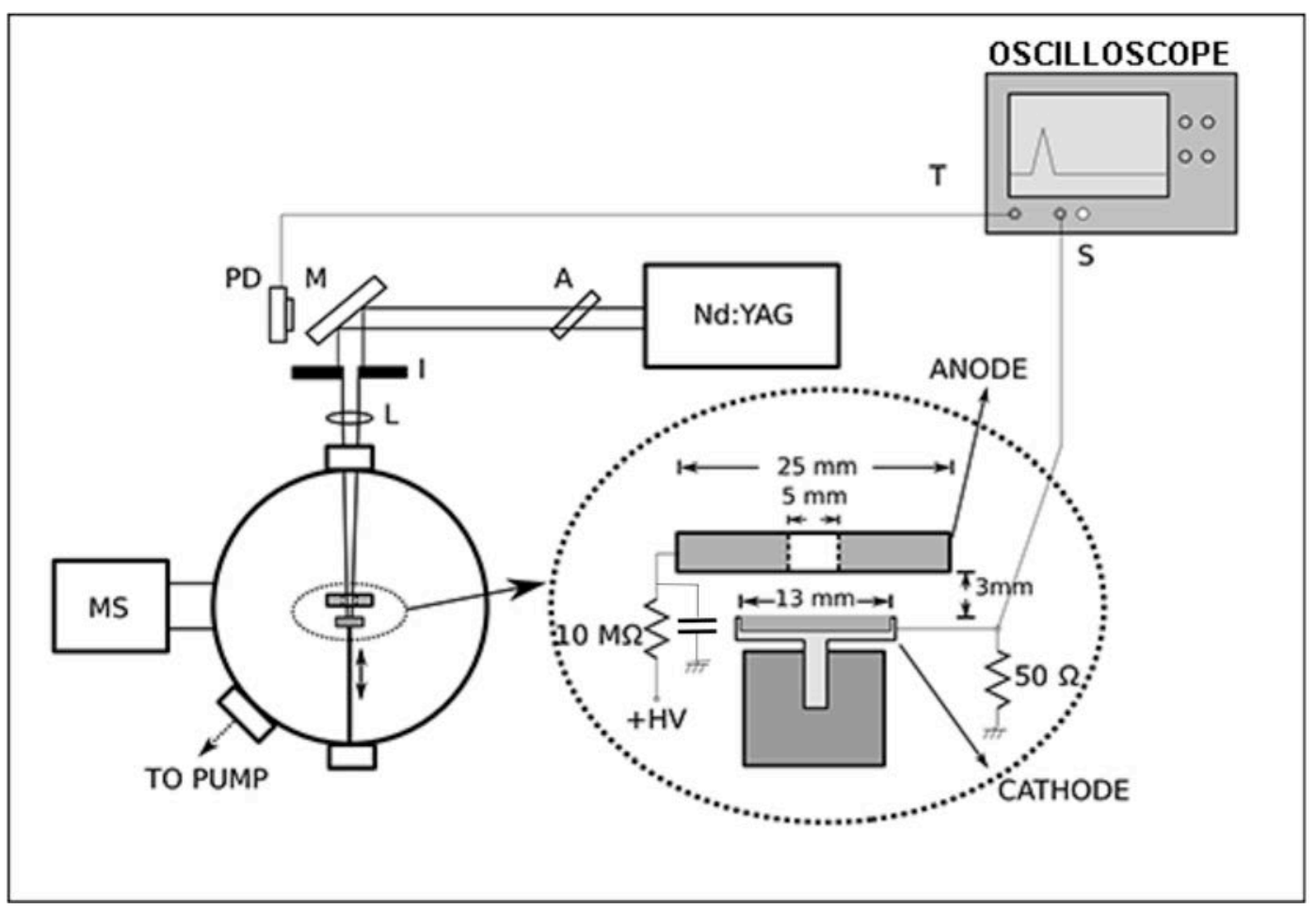

Figure 1 

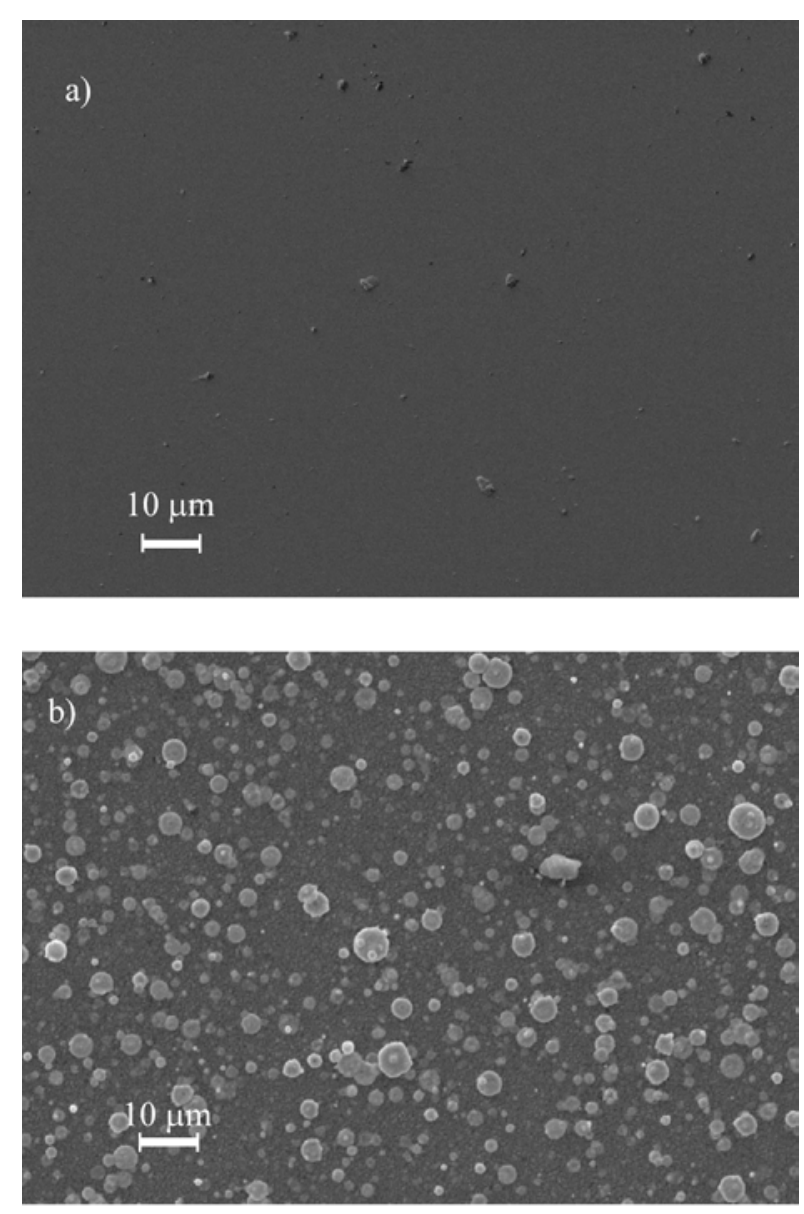

Figure 2 

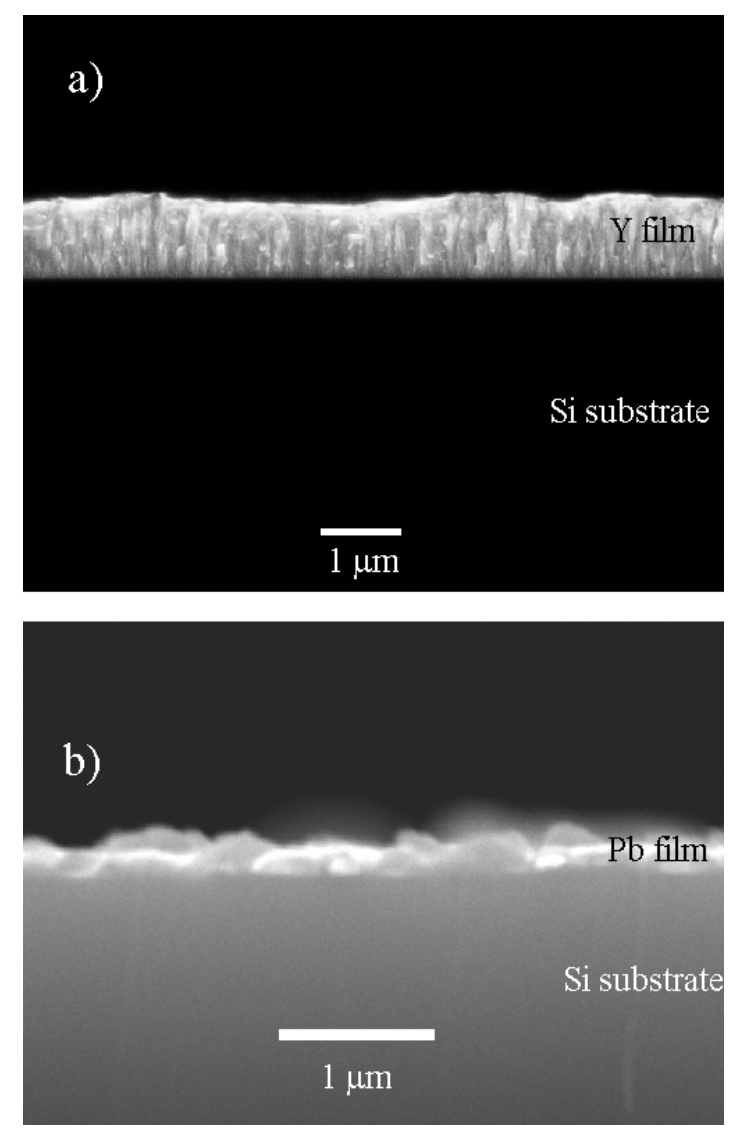

Figure 3

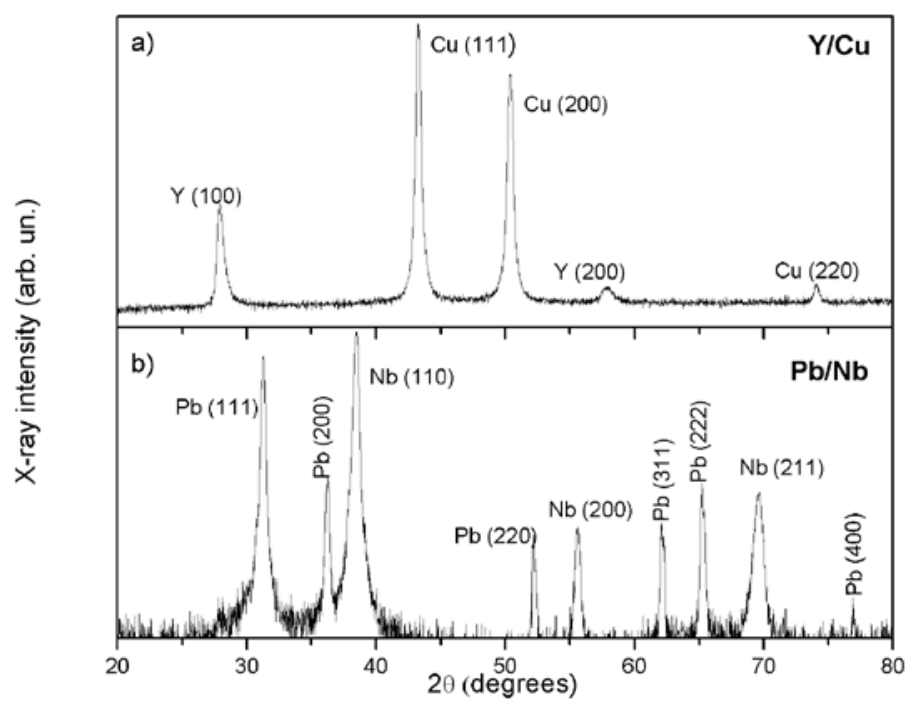

Figure 4 

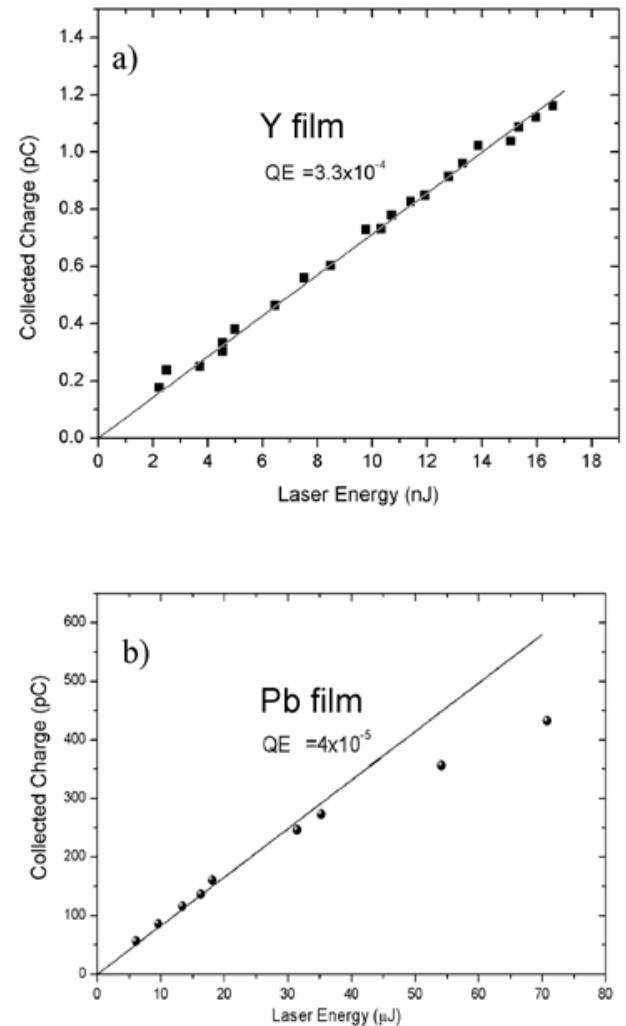

Figure 5 